\title{
An assessment of the unconditioned stimulus properties of reward and nonreward odor cues
}

\author{
STEPHEN F. DAVIS, SUSAN M. NASH, KIRK A. YOUNG, MELANIE S. WEAVER, \\ BRENDA J. ANDERSON, and JOANN BUCHANAN \\ Emporia State University, Emporia, Kansas
}

\begin{abstract}
Two experiments designed to assess defensive burying of reward $(R)$ and nonreward $(N)$ odors by rats are reported. Experiment 1 demonstrated that odor-experienced animals spent more time contacting and aggressing toward (i.e., biting) an $\mathrm{N}$-odor stimulus than an R-odor stimulus. Experiment 2 employed naive animals and replicated the Experiment 1 pattern of results. Thus, these studies demonstrate that $\mathbf{R}$ and $\mathbf{N}$ odors will elicit differential (Experiments 1 and 2), unconditioned (Experiment 2) responding. The complete absence of defensive-burying responding in both experiments suggests that the $\mathrm{N}$-odor stimulus may not be sufficiently intense to elicit this response.
\end{abstract}

Subsequent to the publication by Ludvigson and Sytsma (1967) of data suggesting that rats exude qualitatively and/or quantitatively distinct odors on reward (R) and nonreward $(\mathrm{N})$ trials, a rather impressive body of literature has been generated in support of this "odor hypothesis." For example, it has been demonstrated that rats are capable of appropriate responding under a randomly determined daily $\mathrm{R} / \mathrm{N}$ schedule when odor cues are maximized (Davis, Prytula, \& Voorhees, 1979). Similarly, Morrison and Ludvigson (1970) reported evidence indicating that such odors can be used effectively as discriminative cues for appropriate T-maze performance. More recently, Collerain (1978), Collerain and Ludvigson (1977), and Davis, Whiteside, Bramlett, and Petersen (1981) have attempted to provide a theoretical base for these odors by linking them and their production to frustration theory (Amsel, 1958, 1962). Further verification of $\mathrm{R}$ and $\mathrm{N}$ odors has been provided by Voorhees and Remley (1981). Recording from single mitral cells in the rat's olfactory bulb, Voorhees and Remley reported the existence of two specific (yet possibly similar in chemical structure) odors of $R$ and $N$ that were different from the odors of food and urine.

It has been further demonstrated that $\mathrm{R}$ and $\mathrm{N}$ odors may serve to elicit unconditioned approach and avoidance responses, respectively (e.g., Collerain \& Ludvigson, 1972; Mellgren, Fouts, \& Martin, 1973). For example, Mellgren et al. reported that when odor-donor subjects were placed in a chamber and allowed to exude an $\mathrm{R}$ or an $\mathrm{N}$ odor, subsequent test subjects displayed faster escape speeds to $\mathrm{N}$ odors than to $\mathrm{R}$ odors. The present experiments were conducted to yield additional information regarding the attractiveness and aversiveness of $R$ and $\mathrm{N}$ odors in a situation other than spatial avoidance.

The authors' mailing address is: Department of Psychology, Emporia State University, Emporia, Kansas 66801.
Numerous studies (e.g., Anderson, Nash, Weaver, \& Davis, 1983; Davis, Grady, Klaess, Petty-Zirnstein, \& Tramill, 1983; Goldberg, Chezzi, \& Cheney, 1983; Oberdieck \& Tarte, 1981) have demonstrated clearly that rats afforded the opportunity will employ a variety of materials (Pinel \& Treit, 1979) to bury a variety of aversive stimuli (see Davis, Whiteside, Dickson, Heck, \& McKnab, 1982; Terlecki, Pinel, \& Treit, 1979; Wilkie, MacLennan, \& Pinel, 1979). If $\mathrm{N}$ odors are, in fact, unconditioned aversive stimuli, then one might predict that the defensive-burying response might be directed toward an N-odor stimulus. On the other hand, the nature of the response that might be directed toward an $\mathrm{R}$-odor stimulus is not as clear. If $\mathrm{R}$ odors are perceived as positive stimuli to be approached, then one might predict that this stimulus would be contacted repeatedly in some nonaggressive manner. On the other hand, it may be that the R-odor stimulus is viewed as a "safe" or nonthreatening stimulus, thus allowing the animal to explore other aspects of the test chamber.

\section{EXPERIMENT 1}

The purpose of Experiment 1 was to determine whether or not the proposed odor-collection procedure was effective and would result in differential responding. To accomplish this, a group of odor-experienced animals that had been previously trained in a runway experiment was employed. One subgroup of these animals continued to receive daily runway training under a daily odor-maximizing, double-alternation (i.e., RRNNRRNN) schedule. For these animals, the runway was modified via the attachment of absorbent padding to the goalbox floor. This padding, when selectively removed following $\mathrm{R}$ or $\mathrm{N}$ runway trials, served as the test stimulus in the defensive-burying situation. The remainder of the odorexperienced animals served as defensive-burying test subjects. 


\section{Method}

Subjects. Twelve 120-day-old male Holtzman rats served as the subjects. All animals had served previously as subjects in a runway experiment and were odor experienced (i.e., visual inspection of their data indicated that appropriate odor-based patterning had been established by each animal). The subjects were caged individually and were maintained on the fooddeprivation regimen ( $85 \%$ free-feeding body weight) that had been used in the runway study. Water was freely available at all times.

Apparatus. Runway training for the odor-donor animals took place in a single, straight runway (more fully described by Weaver, Whiteside, Janzen, Moore, \& Davis, 1982) with a gray startbox and black run and goal sections. Masonite guillotine doors separated the start and goal sections from the run section. Start, run, and goal times were produced on all trials. Odor-free, absorbent padding $(254.00 \mathrm{~mm}$ long $\times 50.80 \mathrm{~mm}$ wide $\times 1.59 \mathrm{~mm}$ thick) with three adhesive strips on the back was affixed to the goalbox floor.

Defensive-burying testing took place in a rectangular glass and Plexiglas enclosure (more fully described by Anderson et al., 1983) with a 4-cm layer floor of San-I-Cel bedding material (Paxton Processing Co., Paxton, Illinois). The defensive-burying apparatus was not located in the same experimental room as the runway. Electronic digital timers (Lafayette Model 54030) were used to time each test session and the duration of defensive burying and contact, respectively, with the odor stimulus.

Procedure. Two squads of animals, odor donors $(n=4)$ and test subjects $(n=8)$, were formed randomly at the inception of the study. During the 4 days of experimental testing, the four odor donors received daily runway training under the RRNNRRNN schedule ( $R=1245-\mathrm{mg}$ Noyes pellets, $\mathrm{N}=30$-sec confinement). These subjects were run in a fixed sequence on all days, with Trial 1 being administered to all subjects before Trial 2 was administered, etc. To maximize odor accumulation, the first two $\mathrm{R}$ trials were administered to all subjects before the absorbent padding (odor stimulus) was removed from the goalbox. At this point, the runway was swabbed and allowed to air dry with the lids open. Then the next two $\mathrm{N}$ trials were administered to all subjects. The $\mathrm{N}$-odor stimulus was then removed, and the apparatus was swabbed and dried in preparation for the next two trials. Thus, four (two $\mathrm{R}$ and two $\mathrm{N}$ ) odor stimuli were produced daily. When each odor stimulus was removed from the goalbox, the absorbent padding was rolled into a cylinder and secured with a rubber band. Prior to placement in the defensive-burying apparatus, each odor stimulus was placed in an airtight plastic bag to ensure its potency. Thus, four of the test animals received defensive-burying testing each day, with two animals receiving an $\mathrm{R}$ stimulus and two animals receiving an $N$ stimulus. (The assignment of animals to the initially encountered $\mathrm{R}$ or $\mathrm{N}$ stimulus was determined randomly.) Hence, by the completion of Day 2, all subjects had been exposed to one odor stimulus (either $\mathrm{R}$ or $\mathrm{N}$ ) in the defensive-burying apparatus. In order to ascertain (1) any unique effects attributable to initial contact with an odor stimulus and (2) differential effects resulting from exposure to both stimuli, two additional days of testing were administered. On these days, each subject received the odor stimulus that had not been experienced previously (i.e., if an $\mathrm{N}$ stimulus was administered to a subject on Day 1 , then this subject received an $R$ stimulus on Day 3, and so forth).

To conduct a defensive-burying test session, the appropriate odor stimulus was inserted (approximately $25 \mathrm{~mm}$ deep) into the bedding material in the center of the defensive-burying chamber. The test subject was immediately placed in the chamber such that the subject was facing away from the odor stimulus, and a 15-min session timer was activated. During this 15 -min session, two independent observers recorded the time of contact (i.e., touching the stimulus with some portion of the body) with the odor stimulus, the time each subject engaged in defensive burying (movement of bedding material toward and/or over the odor stimulus), and the number of bites each subject directed toward the odor stimulus. The observers were not aware of which odor stimulus was being employed on any defensive-burying trial.

\section{Results and Discussion}

Given high interobserver reliability $(r=.94)$, the two time-of-contact scores and number-of-bites scores were averaged for each subject for each trial. Two separate subjects $x$ treatments $x$ treatments analyses of variance incorporating type of odor stimulus ( $R$ vs. $N$ ) and stimulus presentation sequence (first vs. second) factors were performed on the time-of-contact and number-ofbites data. (It should be noted that all subjects failed to display any evidence of defensive burying.)

The time-of-contact analysis yielded significance $[F(1,5)=7.82, p<.05]$ for the type of stimulus ( $R$ vs. N) factor. Visual inspection of these data indicated that the subjects spent more time in contact with the $\mathrm{N}$ stimulus (mean $=234.01 \mathrm{sec}$ ) than with the $\mathrm{R}$ stimulus $($ mean $=61.97 \mathrm{sec})$. Likewise, the analysis of the numberof-bites data yielded significance $[F(1,5)=6.93, p<$ .05] only for the type of stimulus factor, with significantly more bites being directed toward the $\mathrm{N}$ stimulus $($ mean $=54.63)$ than the $R$ stimulus $($ mean $=12.75)$.

Thus, even though defensive burying was not displayed, the results of Experiment 1 clearly indicate that $\mathrm{R}$ - and N-odor stimuli are capable of eliciting differential responding in situations other than the straight runway. More specifically, $\mathrm{N}$ odors elicited increased time of contact and aggressive behavior (bites). However, given that these subjects were already odor experienced, it is possible that these conclusions may not apply to naive animals. Even though somewhat unexpected, the complete lack of defensive-burying responding may suggest the possibility that the aversive stimulus must result in some more directly perceived insult by the animal [e.g., electric shock (Pinel \& Treit, 1978, 1979); the discharge of a flashbulb (Davis \& Rossheim, 1980)] before this response is elicited. On the other hand, since Pinel, Gorzalka, and Ladak (1981) showed that rats will bury anesthetized conspecifics with a small amount of putrescine (an olfactory stimulus) sprinkled on them, it may be that $\mathrm{N}$ odor is simply not intense enough to elicit this response.

\section{EXPERIMENT 2}

As noted, Experiment 1 clearly established the fact that animals will respond differentially to $\mathrm{R}$ and $\mathrm{N}$ odors in a situation other than the straight runway. However, because odor-experienced animals were employed in Experiment 1, these results could not address the question of whether such odors serve as unconditioned stimuli. Through the use of independent groups of naive test animals, Experiment 2 was designed to investigate this question.

\section{Method}

Subjects. Eighteen naive male Holtzman rats served as the defensive-burying test animals. Six odor-experienced male Holtzman rats that received continued runway training and 
neutral-box placements served as the odor donors for the 18 naive test animals. All subjects were caged individually. Water and food were freely available for the defensive-burying test subjects. The odor donors were continued on a food-deprivation regimen that maintained them at $85 \%$ free-feeding body weight.

Apparatus. The runway and defensive-burying chamber employed in Experiment 1 also were used in Experiment 2. A Lafayette activity-monitor chamber (Model 86010) with three aluminum walls and one Plexiglas wall was used for neutralodor placements. This chamber was located in the same experimental room as the runway.

Procedure. Three groups $(n=6)$ of defensive-burying test animals, Groups NS (neutral stimulus), RS (reward stimulus), and NRS (nonreward stimulus), were formed randomly prior to the start of the experiment. Each of the subjects in these groups received an individual 15-min defensive-burying test session in the same manner as that described in Experiment 1, with the exception that each subject was exposed only to the stimulus corresponding to its particular group designation. As in Experiment 1 , the experimenters conducting the defensive-burying trials were unaware of which odor sitmulus was in place on any given trial.

The neutral-odor stimuli were collected from the donor animals prior to the administration of daily runway training. The neutral-placement procedure consisted of individually placing each donor subject, in the same fixed order that had been used for the administration of runway trials, in the neutralplacement box for $30 \mathrm{sec}$. After each subject had received two placements, the absorbent padding was removed and placed in an airtight plastic bag. Two neutral-odor stimuli were collected daily. The procedure for collecting $\mathrm{R}$ and $\mathrm{N}$ odor stimuli was similar to that employed in Experiment 1 (i.e., two $\mathrm{R}$ and two $\mathrm{N}$ stimuli were collected daily). Hence, a total of six burying test animals (two neutral odor, two $\mathrm{R}$ odor, and two $\mathrm{N}$ odor) were run on each of the 3 days of experimental testing. The test subjects were assigned randomly to the odor-stimulus condition that they had experienced in the defensive-burying situation.

\section{Results}

Because defensive burying was completely absent in Experiment 1, both observers recorded time of contact and number of bites that each subject directed toward its odor stimulus during the 15-min test session. Prior to analysis, the data from the two observers were averaged to yield single time-of-contact and number-of-bites scores for each subject. These scroes were used for graphing and analysis purposes. Figure 1 shows the mean time-of-contact and number-of-bites for Groups NS, RS, and NRS. Analysis of variance of the number-of-bites data yielded a significant $[\mathrm{F}(2,15)=7.82, \mathrm{p}<.01]$ groups effect. The Newman-Keuls procedure was used to ascertain specific group differences and indicated that Groups NRS and NS bit the odor stimulus significantly $(\mathrm{p}<.01)$ more than did Group RS, but did not differ reliably between themselves. Analysis of variance of the time-of-contact data also yielded a significant $[\mathrm{F}(2,15)=$ 7.06, $\mathrm{p}<.01]$ groups effect. Subsequent NewmanKeuls tests indicated that Groups NS and NRS spent significantly $(\mathrm{p}<.05)$ more time contacting the odor stimulus than did Group RS.

\section{GENERAL DISCUSSION}

The Experiment 2 finding that Group NRS spent significantly more time in contact with and directed more bites toward
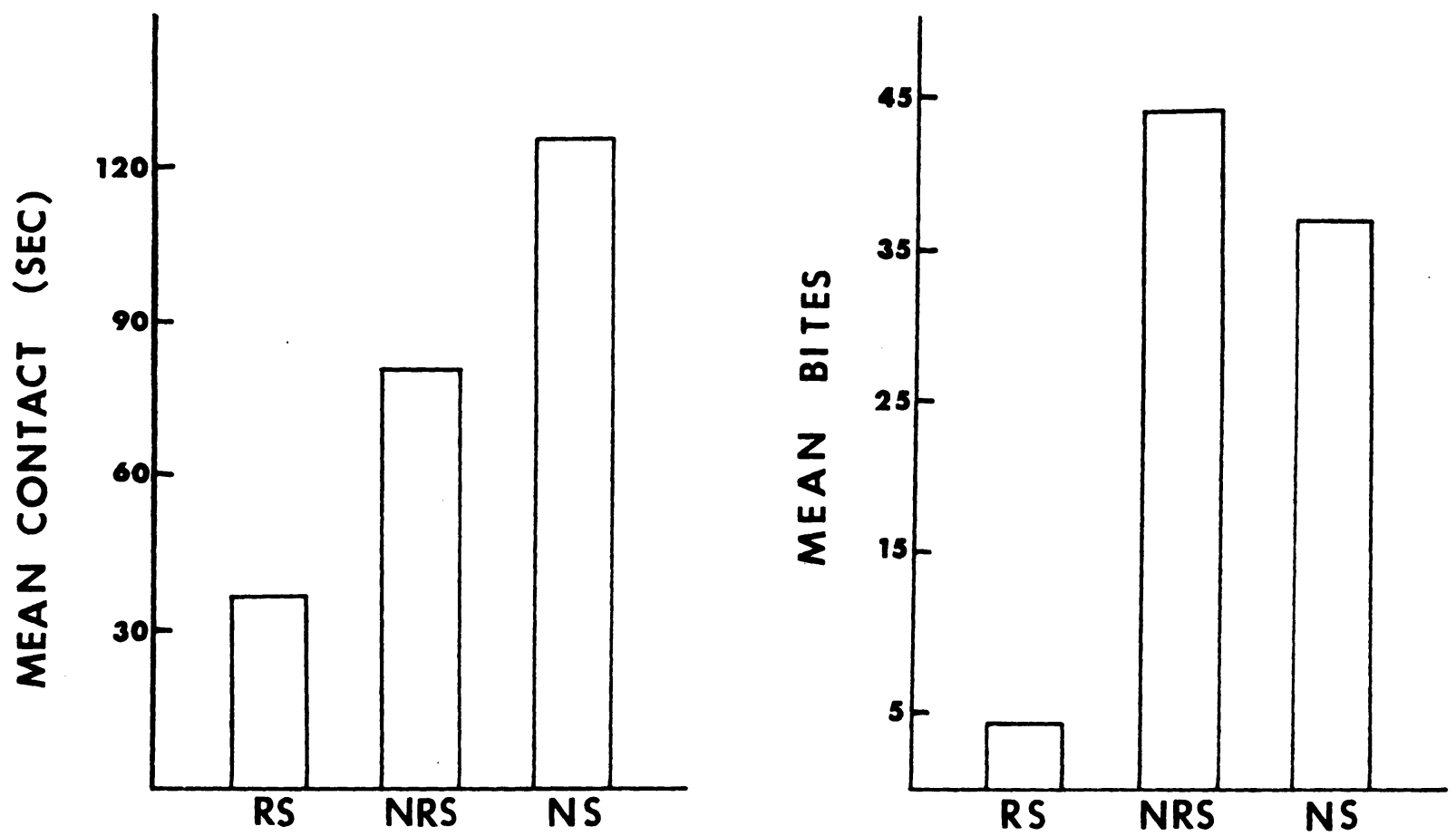

\section{GROUPS}

Figure 1. Mean time of contact (left panel) and number of bites (right panel) directed toward the odor stimulus by Groups RS (reward stimulus), NRS (nonreward stimulus), and NS (neutral stimulus) in Experiment 2. 
the odor stimulus is in agreement with the results of Experiment 1 (see Figure 1). It is interesting to note, however, that both the time-of-contact and the number-of-bites scores for both of these groups are lower than the corresponding scores recorded in Experiment 1. Since odor-experienced animals were used in Experiment 1, this observation suggests that prior exposure to and knowledge of $\mathrm{R}$ and $\mathrm{N}$ odors serves to intensify the unconditioned reactions manifested in Experiment 2. The fact clearly remains, however, that $\mathbf{R}$ and $\mathbf{N}$ odors are capable of eliciting differential, unconditioned responding, and that such responding appears to be much more aggressive in the case of $\mathrm{N}$ odors.

Certainly, the high time-of-contact and number-of-bites scores shown by Group NS (neutral odor) in Experiment 2 were unexpected. For several reasons, these data prompt us to suggest that the odors deposited in the neutral-placement box may not have been "neutral" as originally conceptualized. First, the neutral-placement box was located in the same room as the runway apparatus. It is conceivable that the general context of this room aroused an expectancy of reward in the runwaytrained odor donors that generalized to the neutral-placement box. Hence, an $\mathrm{N}$ odor may have been exuded in the neutralplacement box when reward was not received. Second, it is also conceivable that the neutral-placement condition may not have been completely neutral. From the standpoint of the receipt of reward and nonreward, it may have been (but, see above). However, from the standpoint of the animal being transported to and placed in a novel, potentially threatening environment, the neutral-placement condition may have been anything but neutral. Hence, it is possible that some type of alarm or fear odor was exuded there. Obviously, the present experiments are not prepared to offer direct answers to these two possibilities. On the other hand, the responding shown by Group NS (Experiment 2) does not appear to detract from the finding that differential responding was shown to the $\mathrm{R}$ - and $\mathrm{N}$-odor stimuli.

As in Experiment 1, defensive burying was completely lacking in Experiment 2. This lack of defensive burying shown in both experiments, in conjunction with the demonstration by Pinel et al. (1981) that anesthetized conspecifics and wooden dowel rods sprinkled with cadaverine or putrescine were buried, suggests a need for further research regarding the types and/or intensities of olfactory stimuli that elicit defensive burying.

\section{REFERENCES}

Amsel, A. (1958). The role of frustrative nonreward in noncontinuous reward situations. Psychological Bulletin, 55, 102-119.

Amses, A. (1962). Frustrative nonreward in partial reinforcement and discrimination learning: Some recent history and theoretical extension. Psychological Review, 69, 300-328.

Anderson, B. J., Nash, S. M., Weaver, M. S., \& Davis, S. F. (1983). Defensive burying: The effects of multiple stimulus presentation and extinction. Psychological Record, 33, 185-190.

Collerain, I. (1978). Frustration odor of rats receiving small numbers of prior rewarded running trials. Journal of Experimental Psychology: Animal Behavior Processes, 4, 120-130.

Collerain, I. J., \& Ludvigson, H. W. (1972). Aversion of conspecific odor of frustrative nonreward in rats. Psychonomic Science, 27, 54-56.

Collerain, I., \& Ludvigson, H. W. (1977). Hurdle-jump re- sponding in the rat as a function of conspecific odor of reward and nonreward. Animal Learning \& Behavior, 5, 177-183.

Davis, S. F., Grady, S. M., Klaess, A. M., Petty-Zirnstein, M. K., \& Tramill, J. L. (1983). Defensive burying of a classically conditioned stimulus. Psychological Record, 33, 67-75.

Davis, S. F., Prytula, R. E., \& Voorhees, J. W. (1979). Odordonor cue control of runway performance: A further examination. Bulletin of the Psychonomic Society, 13, 141-144.

Davis, S. F., \& Rosshe im, S. A. (1980). Defensive burying as a function of insulin-induced hypoglycemia and type of aversive stimulation. Bulletin of the Psychonomic Society, 16, 229-231.

Davis, S. F., Whiteside, D. A., Bramlett, J. A., \& Petersen, S. H. (1981). Odor production and utilization under conditions of nonreward and small reward. Learning and Motivation, 12, 364-382.

Davis, S. F., Whiteside, D. A., Dickson, V. A., Heck, D. G., \& McKnaB, P. A. (1982). Conditioned defensive burying as a function of stimulus modality and stimulus accessibility. Journal of General Psychology, 106, 101-108.

Goldberg, S. G., Chezzi, P. M., \& Cheney, C. D. (1983). Rat defensive behavior: Burying an operandum associated with reinforcement. Psychological Record, 33, 191-199.

Ludvigson, H. W., \& Sytsma, D. (1967). The sweet smell of success: Apparent double alternation in the rat. Psychonomic Science, 9, 283-284.

Mellaren, R. L., Fouts, R. S., \& Martin, J. W. (1973). Approach and escape to conspecific odors of reward and nonreward in rats. Animal Learning \& Behavior, 1, 129-132.

Morrison, R. R., \& Ludvigson, H. W. (1970). Discrimination by rats of conspecific odors of reward and nonreward. Science, 167, 904-905.

Oberdieck, F., \& TARTe, R. D. (1981). The effect of shock prod preexposure on conditioned defensive burying in rats. Bulletin of the Psychonomic Society, 17, 111-112.

Pinel, J. P. J., Gorzalka, B. B., \& Ladak, F. (1981). Cadaverine and putrescine initiate the burial of dead conspecifics by rats. Physiology \& Behavior, 27, 819-827.

Pinel, J. P. J., \& Treit, D. (1978). Burying as a defensive response in rats. Journal of Comparative and Physiological Psychology, 92, 708-712.

Pinel, J. P. J., \& Treit, D. (1979). Conditioned defensive burying in rats: Availability of burying materials. Animal Learning \& Behavior, 7, 392-396.

Terlecki, L. J., Pinel, J. P. J., \& Treit, D. (1979). Conditioned and unconditioned defensive burying in the rat. Learning and Motivation, 10, 337-350.

Vorhees, J. W., \& Remley, N. R. (1981). Mitral cell responses to the odors of reward and nonreward. Physiological Psychology, 9, 164-170.

Weaver, M. S., Whiteside, D. A., Janzen, W. C., Moore, S. A., \& DAvis, S. F. (1982). A preliminary investigation into the source of odor-cue production. Bulletin of the Psychonomic Society, 19, 284-286.

Wilkie, D. M., Maclennan, A. J., \& Pinel, J. P. J. (1979). Rat defensive behavior: Burying noxious food. Journal of the Experimental Analysis of Behavior, 31, 299-306.

(Manuscript received for publication December 25, 1983.) 